\title{
新课标下探讨数形结合思想渗透在小学数学教学中的重要性
}

余爱萍

甘肃省张掖市甘州区青西小学

DOI:10.32629/jief.v2i9.1776

[摘 要] 随着新课改进程的逐步推进, 教学形式也在发生不断的变化, 小学教育作为整体教育中重要的部分, 其对一个人的成长和成才具有 较为显著的影响。小学阶段的数学学科更是一门非常重要的学科, 所以在教学过程中应采取有效且创新的教学方式, 令小学生学到更多知识。 数形结合的教学方式就是现今比较常用的方式, 将课堂的教学与数形结合进行融合, 可在一定程度上填补传统教学方式的缺陷。对此, 本文 主要从数形结合思想渗透在小学数学教学中的策略出发, 简要分析了其在教学中发挥的重要性, 以期促进小学生数学成绩的提高。

[关键词] 新课标; 数形结合思想; 小学数学教学; 重要性

中图分类号: G623.5 文献标识码: A

数形结合的教学方式主要是指在数学教学中将数字与图形进行结 合。图形与数字本身为对应关系, 将这种关系运用到数学中, 就是转换 位置、图形、数量与数字之间的关系, 而后达到复杂变简单、抽象变直 观的目的, 这种方式主要可以帮助学生完成分析、理解和解决问题等行 为。对小学生来说, 相比枯燥且单调的文字或数字, 其更加喜欢直观且 容易理解的图形, 所以将数形结合思维运用到数学教学中, 对小学生来 说百利而无一害。就此情况, 本文主要立足于数形结合思想的数学教学 方式, 对其重要性进行了分析和探讨。

\section{1 降低了理解数学知识的难度}

在新课标的教育背景下, 将数形结合思想渗透到数学教学中, 在一 定程度上可以降低理解数学知识的难度。在教学的过程中, 教师利用图 形将相关的数学知识呈现出来, 变抽象为直观和简单, 可以令学生对问 题进行充分的理解, 进而加深其对数学知识的体会。例如, 在导入 《两 位数乘一位数的笔算乘法》一课时, 教师可先列举几张关于口算的卡片: “ $4 \times 2=? 6 \times 2=? 20 \times 2=$ ? ” 而后令学生进行口算; 而后还可引导学 生们进行图片的观察, 而后根据图片内容导出利用乘法对数学问题进行 解决的方式。因现今正处于高科技时代, 所以可以借助网络的力量, 通 过播放视频等方式将数学知识清晰化地展示在学生面前。这种方式可引 导学生积极参与, 提高其兴趣, 而后快速融入课堂之中, 通过这样的方 式, 学生们可以学会独立思考以及共同合作, 了解计算方式的多样化, 进而提高自身逻辑思维能力和解决问题的能力。

\section{2 使学生们的数学空间思维能力得到培养}

在实际的数学教学阶段, 形式化的教学方式并不可取, 所以利用数 形结合的方式带动学生解题积极性, 可以充分提高学生们的逻辑思维能 力。在进行教学的过程中, 还应结合实际情况, 利用数学计算对相关几 何图形的问题进行解答, 令小学生的空间思维能力得以提高。例如, 在 进行《初步认识锐角和钝角》的学习时, 教师可以将制作好的课件进行 展示, 令学生拿出准备好的三角尺, 将其与书中的直角进行比较, 而后 讲述自己的发现。通过这样的方式, 可以培养学生们动手操作的能力, 而后激发其对数学知识的兴趣和探究欲, 在这样的课堂活动中, 学生可 以更加简单且直观地了解到直角、锐角以及针角的特征, 还可形成空间 观念, 对小学生逻辑能力和想象力的培养都有一定的重要性。

\section{3 将数学概念及知识具象化}

数学本身就属于较为抽象的科目, 小学生之所以对数学不感兴趣, 不仅是因为其枯燥且乏味的题目, 还因为这些题目较为抽象, 小学生无 法理解, 此时如果教师采取程式化的教学模式对其进行重复的教学, 只 会引起学生的逆反心理, 进而更加厌烦数学。因此, 教师们应考虑到这 种情况, 通过数形结合的思想, 将数学知识具象化。例如, 在进行 《分 数的基本性质》一课教学时, 教师可将学生们进行分组, 为每组分发一 个已经准备好的 “圆形纸板”, 圆形纸板上需涂上代表分割的阴影, 这些 道具需大小一致, 而后令学生们观察和动手, 将圆形分成多个部分, 而 后通过这些介绍分数的概念。通过这种方式可以令学生们更快速的了解 数学知识, 掌握难懂的抽象问题。这样动手操作的方式对教师来说也有 一定益处, 其可以与学生进行充分交流, 而后了解其学习的情况, 以方 便进行下一步教学。

\section{4 数形结合思想的应用意义}

数形结合思想有利于提高抽象知识记忆, 现今的小学生所掌握的知 识大都来自现实客观事物, 这些都便于理解且较为直观。但在数学课本 中, 有些知识并非完全直观, 尤其是现在的课本知识难度逐步加大, 所 以很多知识更加趋于抽象化, 学生在理解时存在诸多问题。而数形结合 的方式正可以帮助学生解决这一问题, 在此过程中, 学生可轻松掌握新 知识, 并提高记忆, 达到较为客观的学习效果。

另外, 其还有助于提高学生解题能力, 数形结合的教学方法可在一 定程度上将题目难度降低, 学生利用此方法可快速解题, 并找到新的思 路, 进而提高解题能力。

\section{5 结束语}

总而言之, 小学数学对小学生来说属于较为晦涩难懂的科目, 所以 在教学过程中更应采取合适的方式。在新课标教育背景下, 将数形结合 思想渗透到小学数学教学中, 对小学生的数学能力提高具有重要意义。

\section{[参考文献]}

[1]韩召贵.关于小学高年级数学作业多元化设计的策略研究 [J].新 课程 (小学) .2016(11):266.

[2] 罗芳婷. 陈上仁. 农村小学数学作业设计的问题、原因和对策研究 [J].教育教学论坛.2013(46).

[3]唐玉华. 小学语文教师阅读指导力提升策略 [J]. 新课 程,2020(34):46. 